AC 2010-2267: INCORPORATING VERY POWERFUL STRUCTURAL ANALYSIS AND DESIGN SOFTWARE PACKAGES INTO CIVIL ENGINEERING COURSES

Mohammad Alhassan, Indiana University Purdue University, Fort Wayne

James Welch, Indiana-Purdue University Fort Wayne (IPFW) 


\title{
Incorporating Very Powerful Structural Analysis and Design Software Packages into Civil Engineering Courses
}

\begin{abstract}
Extensively used in the continuous series of undergraduate structural analysis and design courses, SAP2000 and ETABS have helped the civil engineering students gain real world experience with some of the most powerful software packages available to professionals. Allowing students to learn the software step by step (modeling, analysis, and design) in a sequential approach through successive interrelated core and elective courses (Structural Analysis, Reinforced Concrete Design, and Steel Design), supplies the students with the fundamentals needed to tackle large projects on their own. This paper illuminates the various learning projects that were given to the students in the courses mentioned above. The paper continues with a demonstration to a practical application as civil engineering students used SAP2000 to design a pedestrian bridge for the required capstone senior design course. The project allowed the students to further explore the various design capabilities of SAP2000 while moving past the seemingly simple static load conditions, and proceeding to more complex dynamic and nonlinear analysis of the proposed pedestrian bridge. Using the background from earlier courses and the online help menu provided by the software, the group was able to successfully model, analyze, and design the pedestrian bridge in accordance with the AASHTOLRFD requirements.
\end{abstract}

\section{Introduction}

The major conundrum of engineering educators is, with every passing year, the level of technology and practice of engineering increases in its complexity. Accordingly, there will never be enough time to cover all of the required topics in depth ${ }^{1}$. However, it is important for educators to remain current with ongoing trends in their field in order to present a general overview of technologies that are used in the workplace. Numerous studies have been conducted to develop new technologies and methods that can be introduced to students in order to allow them to become successful engineers upon exiting universities. A study performed by Romero and Museros postulated that, “...computer-based analysis programs and computer software for design could play an important role in structural engineering education" in a variety of ways, one of which is using commercial design programs ${ }^{2}$. Allowing students to gain hands-on experience with software packages prior to graduation was the second major theme found in another study that was conducted on practitioners in the field of civil engineering. The first major theme was that those in the field, "... wanted students to be taught the theory, that they be well grounded in fundamentals, and that they be able to do the work by hand without the use of the computer."3

With many recognizing that the effective use of computing is, "...the key to increased individual, corporate, and national productivity", analysis and design software packages, SAP2000 and ETABS, into a continuous series of undergraduate civil engineering courses (structures area) so that the students can gain real world experience inside the class room. Allowing students to learn the software step by step (modeling, analysis, and design) in a sequential approach through successive interrelated core and elective 
courses (Structural Analysis, Reinforced Concrete Design, and Steel Design), supplies the students with the fundamentals needed to tackle large projects on their own. Using the software in a variety of courses allows for the students to further refine these computer skills while they are at the university, thus fulfilling the ABET outcome of, “... an ability to use the techniques, skills, and modern engineering tools necessary for engineering practice."

\section{Structural Analysis Course}

Civil engineering students are first introduced to SAP2000 and ETABS in the Structural Analysis course, a core course in any civil engineering curriculum. SAP2000 is intended for use on structures such as bridges, dams, stadiums, industrial structures, and buildings. ETABS is a special version of SAP2000 that is used mainly for buildings ${ }^{4}$. The power of these software packages comes from their amazing flexibility; from the simplest design of a two dimensional frame, to a complicated bridge/building in three dimensions, to the "Bird's Nest" (Chinese National) Stadium from the Games of the XXIX Olympiad. Its true strength lays in its various analysis options that fall in the range of linear and nonlinear, static and dynamic analyses of three dimensional structures.

Since this is the students' first experience with the software, two 75 minutes-lectures were given by the instructor to explain the various features of the software packages and to go over detailed example. The students were also shown how to use the "Watch and Learn" link on the software company's website. Viewing this tutorial allows the students to become more familiar with the software before they complete the first course project with the following problem statement:

Model and analyze a simply supported truss bridge structure using SAP2000. Show the structure in different views that display the functional capabilities of SAP2000. Briefly describe these views and what they are displaying. Such views should include: the reaction due to dead and live loads, deformed shape, 3-dimensional views of structure, the releases of each structural member, the axial loading of each member, etc.

After the bridge structure is modeled and analyzed according to the given geometry and loads, the class explored the various views and outputs that the software is capable of producing.

Figure 1 shows a three dimensional view produced in SAP2000 while Figure 2 is the deformed view of the bridge structure with the displacements shown at the top. It should be noted that the deformed shapes given by both SAP2000 and ETABS are magnified to allow for the user to better visualize the effects the loads on the structure. 


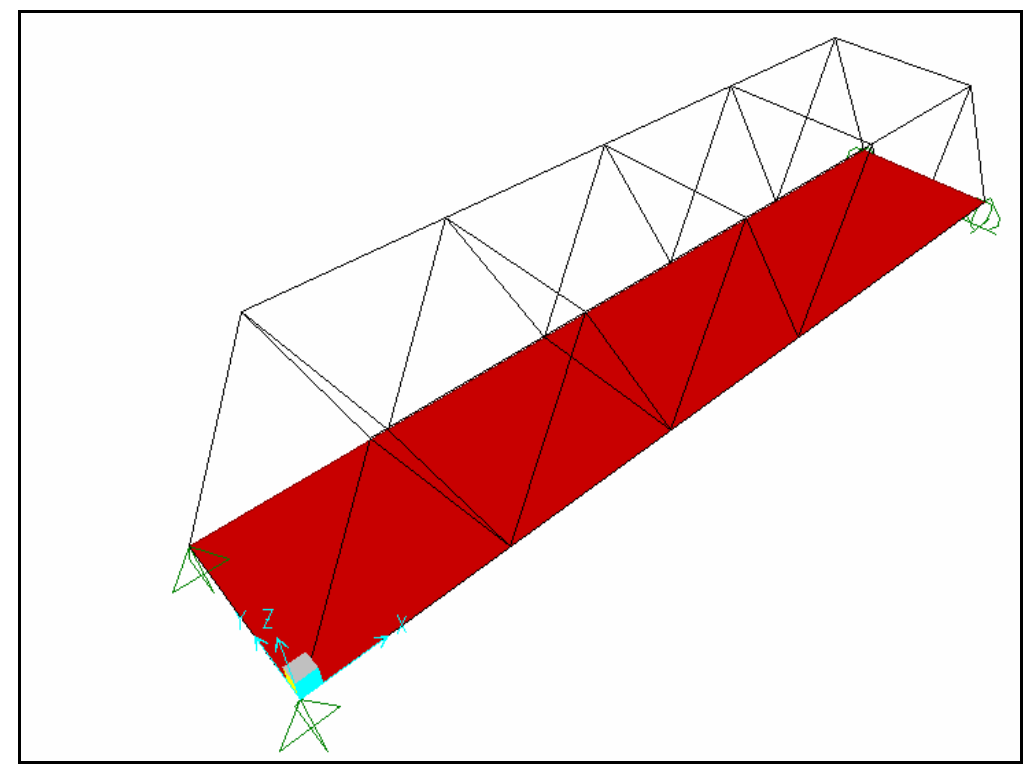

Figure 1. Three dimensional view of the bridge structure.

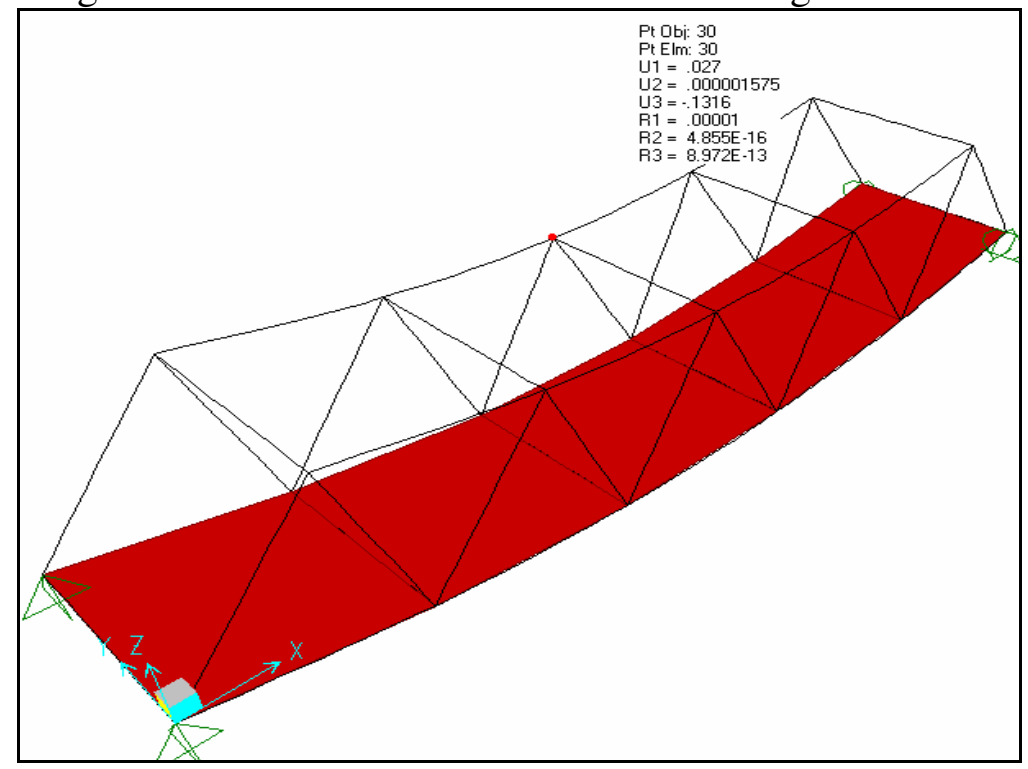

Figure 2. Three dimensional view of the deformed shape of bridge structure.

After obtaining a basic comprehension of computer analysis software through the previous project, the class is given a more in depth project of modeling a three story building in ETABS according to the following requirements:

- The dimensions of the building center to center of the exterior columns are $120 \mathrm{ft} x 90 \mathrm{ft}$.

- The height of the first floor $=15 \mathrm{ft}$, second floor $=15 \mathrm{ft}$, and third floor $=12 \mathrm{ft}$

- The columns and beams will be made of steel, start with Auto-select sections WF

- The columns are hinged at the ground level.

- The connection between the beams and columns are pin-pin

- $\quad$ The building will be analyzed for gravity loads

- $\quad$ The Dead load is the self weight of the members plus 20 psf superimposed dead load

- $\quad$ The live load is $80 \mathrm{psf}$ 
- $\quad$ The roof live load is 50 psf

- Use the default slab over metal deck system in the ETABS

- Use girders along the column centerlines

- Use floor beams (WF) at $10 \mathrm{ft}$ spacing

- Brace the building in the long direction using concentrically braced frame systems along the exterior column lines at the end spans from both sides.

- Brace the building in the short direction using concentrically braced frame systems along the exterior column lines at the mid spans from both sides.

- Make reasonable assumptions for any additional requirements.

To complete this project, the students are grouped together in teams. Using the auto-select steel wide flange beams as was required from the problem statement, the groups modeled the structure as shown in Figure 3. In Figure 3, it is easy to see the differences between column members and beams which are shown in green and yellow, respectively, with the slab over metal deck system being shown in gray. In addition to columns and beams, the groups were also required to add lateral bracing which are in place to stabilize the structure under wind or seismic loading.

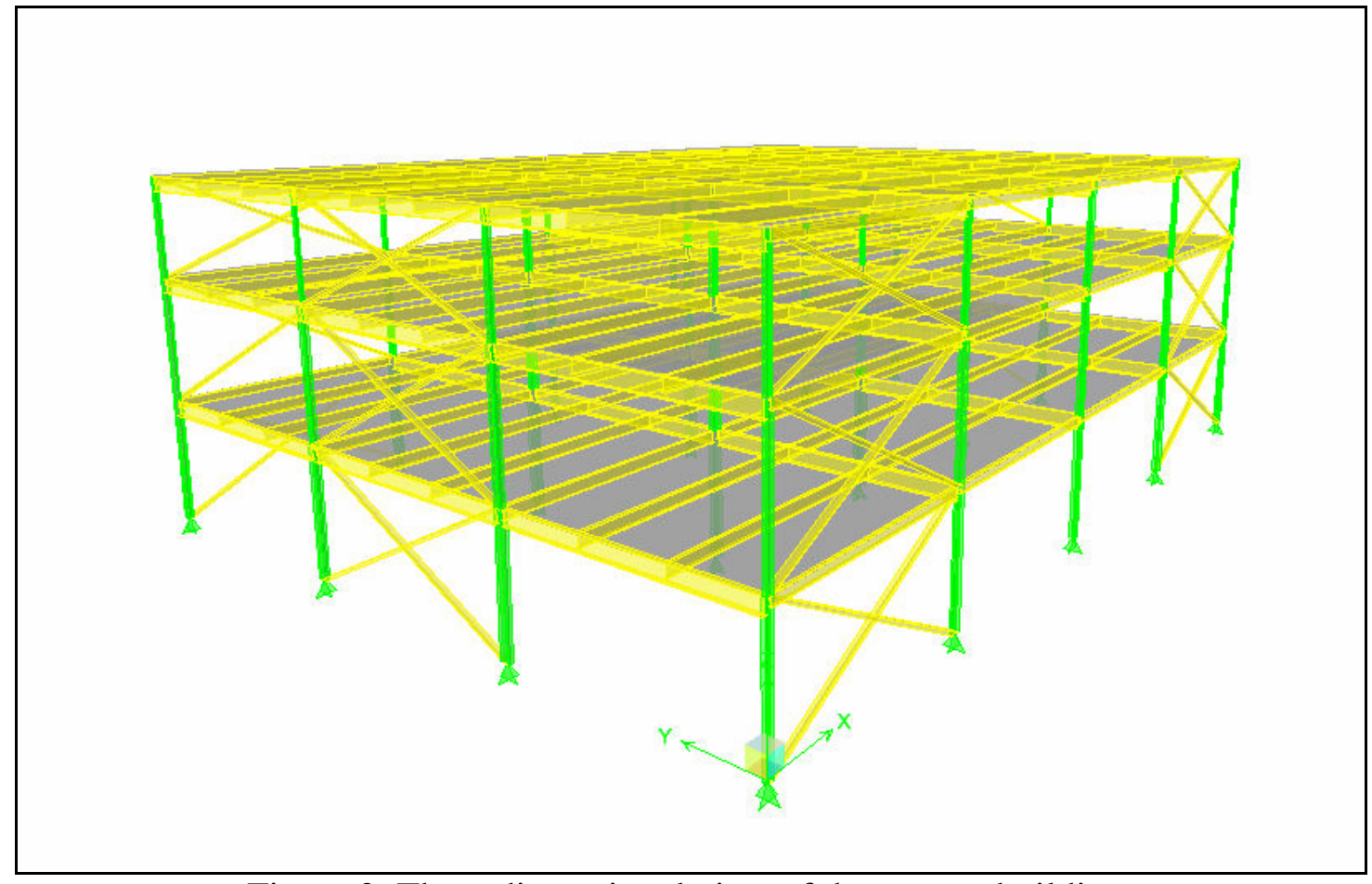

Figure 3. Three dimensional view of three story building.

\section{Design of Reinforced Concrete Structures Course}

The next required use of structural analysis software comes in another core course, Reinforced Concrete Design. In this course, the students were assigned the task of correctly modeling, analyzing, and designing a double-span continuous beam. The problem statement for this project is detailed as follows: 
Use SAP2000/ETABS to design a two span continuous beam with rectangular cross section to carry a service dead load (without self weight) of $1 \mathrm{k} / \mathrm{ft}$ and service live load of $1.2 \mathrm{k} / \mathrm{ft}$. The first span length is $60 \mathrm{ft}$ and the second span length is $40 \mathrm{ft}$. Design the beam according to the ACI Code 318. Assume the beam is pin-connected at the left end and has roller supports between the two spans and at the right end.

Show your analysis and design data from the software. Make sketches to show the cross section details at the maximum negative and positive moment locations. Use concrete strength of 6000 psi and Grade 60 steel for all reinforcements. Make reasonable assumptions for any missing information.

If one without an engineering background was to view this problem statement, the assignment may appear to be trivial; however the students are not far removed from their structural analysis course where, in order to calculate the reactions and forces for a statically indeterminate continuous beam, the only way to analyze the beam would be by using one of the more complex methods of analysis that the students were taught: either the force method of analysis or one of the two displacement methods of analysis (slope-deflection equations or moment distribution). Although each of the students could easily perform these calculations, each of the methods requires considerable amounts of time to perform all of the steps. After spending only a few minutes modeling the assigned beam, the students witnessed how powerful SAP2000 was by eliminating the amount of time required not only to perform one of the methods for a statically indeterminate beam, but also by circumventing the step-by-step approach for reinforced concrete design. As long as the software was initialized correctly, all such tasks can be performed smoothly, with all output being verified by hand calculations. Checking all of the computer analysis by a series of hand calculations goes right in line with the study conducted by Abudayyeh, et al. ${ }^{3}$ Figures 4-6 show screen shots from SAP2000 for the shear and moment diagrams as well as the deflection curve for the two-span continuous beam.

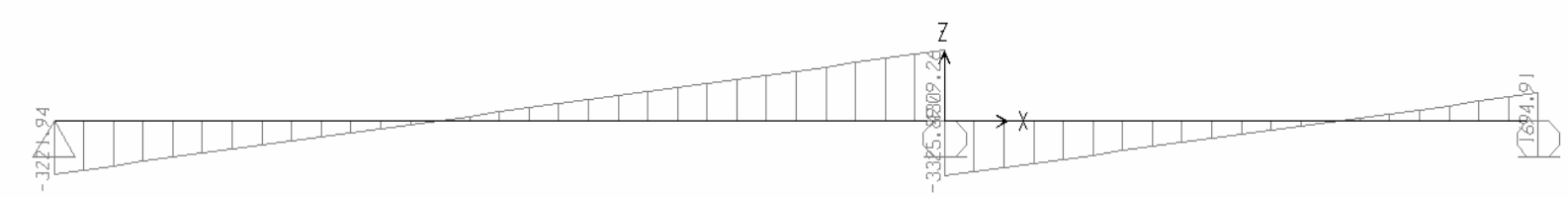

Figure 4. Shear diagram for continuous beam.

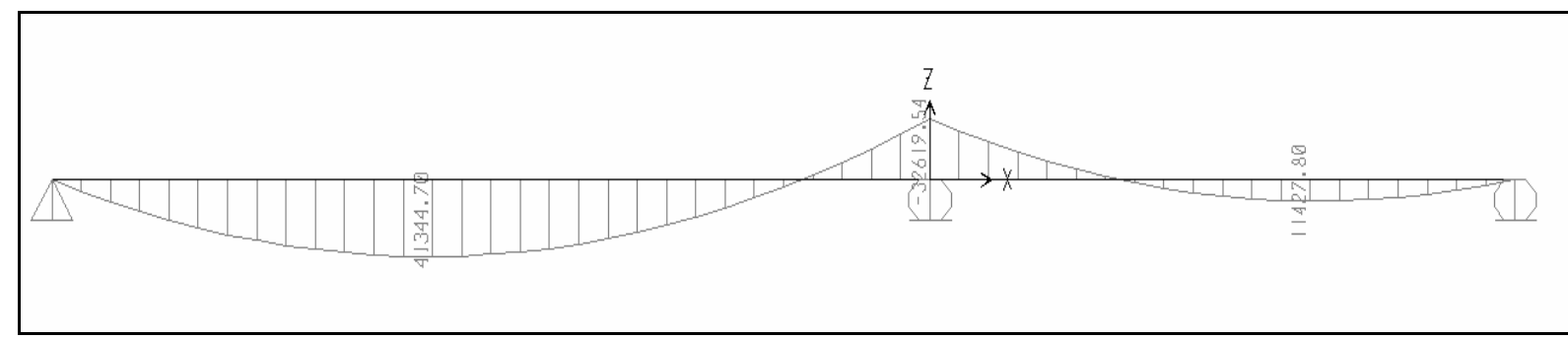

Figure 5. Moment diagram for continuous beam. 


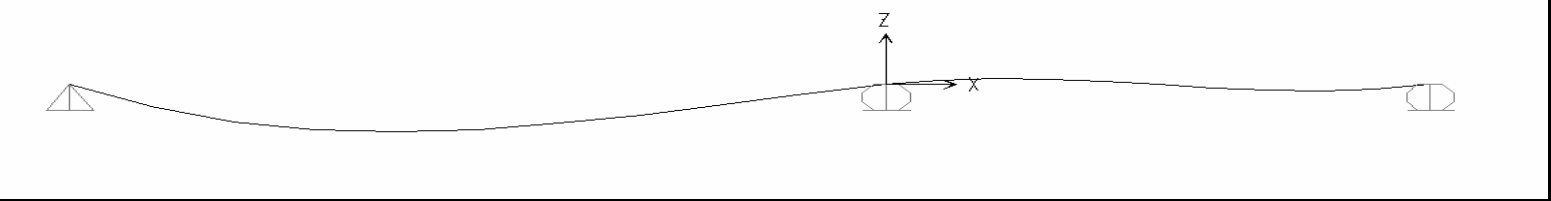

Figure 6. Deflection curve for continuous beam.

In addition to analyzing the two-span continuous beam, the students are also given the project of designing a three story structure using SAP2000/ETABS. This time the students are not only required to model and analyze the three story building, but they are also required to perform a complete design using only reinforced concrete for all of the structural members. With the same project being used in the Structural Analysis course, the problem statement is slightly modified as so:

- The dimensions of the building center to center of the exterior columns are $120 \mathrm{ft} x 90 \mathrm{ft}$.

- $\quad$ The height of the first floor $=15 \mathrm{ft}$, second floor $=15 \mathrm{ft}$, and third floor $=12 \mathrm{ft}$

- The columns and beams will be made of reinforced concrete

- Use square column sections for the corner columns and rectangular sections for the perimeter columns

- Use circular columns for all interior columns

- The columns are hinged at the ground level.

- The connection between the beams and columns are pin-pin

- The building will be analyzed for gravity loads only

- $\quad$ The dead load is the self weight of the members plus 20 psf superimposed dead load

- $\quad$ The live load is 80 psf

- The roof live load is 50 psf

- The slab thickness is 6 in.

- Use girders along the column centerlines

- Use floor beams at $10 \mathrm{ft}$ spacing

- Use 4000 psi concrete and Grade 60 steel for the stirrups and longitudinal rebar

- Make reasonable assumptions for any additional requirements.

This project is similar to one that the students may face when they enter the structural engineering field when a cost analysis must be performed to see whether steel or reinforced concrete is the economical choice for a given project.

\section{Steel Design Course}

In the technical elective course Steel Design, which is typically taken by the students with a passion for the structural engineering field, the students are given more complex projects in comparison to those found in the previous courses. The first project was a truss structure while the second project was the steel design of the same three story residential building that was used in the two core courses. The problem statement for the steel truss is detailed below with Figure 7 showing the dimensions of the truss that is to be designed. 
Use SAP2000/ETABS to design the truss shown below using standard structural steel sections. Due to constructability issues, use the same T section (A992) for all the top and bottom chord members. Use the same double angle section (A36) for all vertical members. Use the same double angle section (A36) for all the diagonal members.

Use the AISC manual to check the software design for the members with the maximum axial forces (top chord member, bottom chord member, vertical member, and diagonal member).

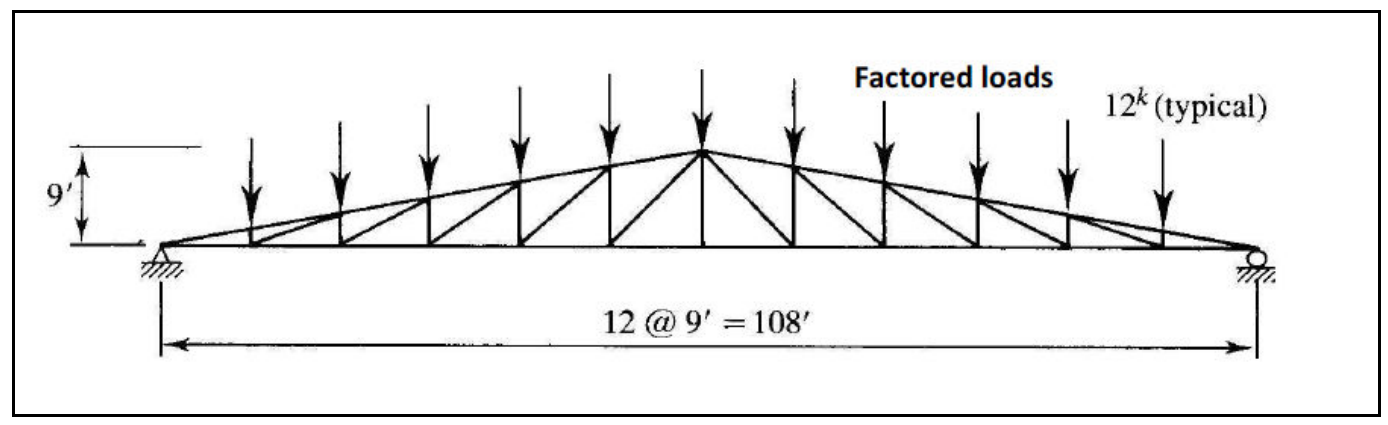

Figure 7. Truss used for steel design project.

Once the truss is designed using the software, the students are required to verify the member sizes by performing a series of hand calculations. Using the fundamentals taught to them through the lectures given in the Steel Design course, students were given the option of either actually writing out manually their hand calculations, or they may design a spreadsheet to neatly perform the same series of calculations. Doing this allows the students to comprehend the fact that they should not rely blindly on computer output, but must instead understand how the software completes the design of a given structural system.

After modeling, analyzing, and designing the above truss in SAP2000/ETABS, the students' next project is to perform a complete structural design of the same three story residential building used in both the Structural Analysis and Reinforced Concrete Design courses. Using the same problem statement that was used for the structure as was used for the second project in Reinforced Concrete Design; the only major difference is that the design was performed using steel members. By initially importing structural steel shapes from the software's built in database, the groups could define each of the members according to a list of auto shapes that can be selected during the software's optimization process. Figure 8 shows the deformed shape of the three story residential structure under its design loads. 


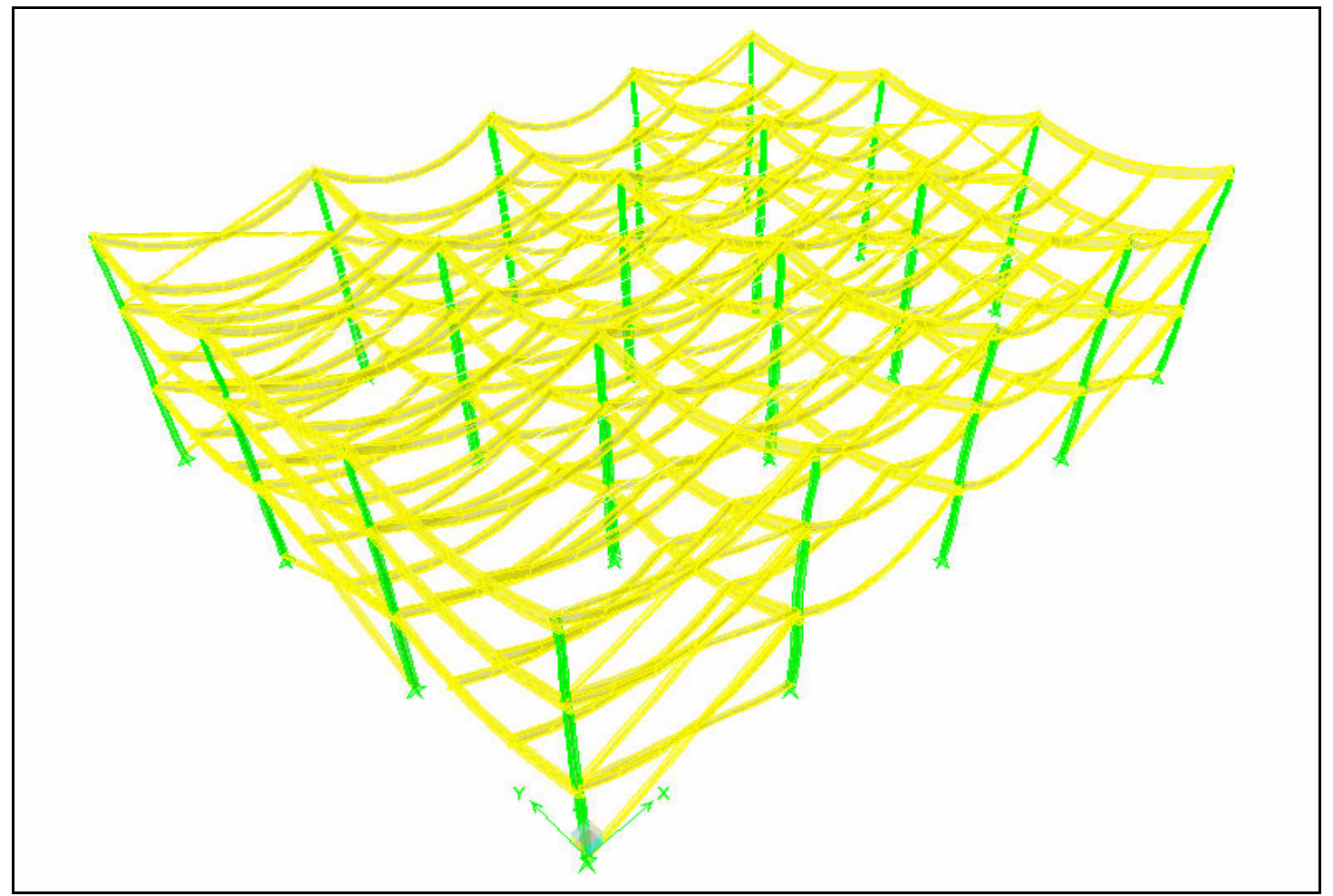

Figure 8. Deformed shape of three-story residential building.

For both of the projects in the Steel Design course, students are required to not only perform the structural design in either SAP2000 or ETABS, but they are also required to perform hand calculations on the structural members. Performing these calculations not only verifies that the students' model of the structure is accurate, it also goes what practitioners hope for in entry levels engineers, "...that they be well grounded in fundamentals, and that they be able to do the work by hand without the use of the computer.",

\section{Senior Design Project}

Using the previous three courses as a foundation, a group of civil engineering students, for their senior design project, decided to design a pedestrian bridge crossing over a main arterial roadway which borders the university campus. According to the Department of Engineering, all senior design capstone projects must adhere to four main objectives. These objectives are:

- To apply knowledge learned in other courses.

- To enhance the thought and planning process

- $\quad$ To expose students to a team design and implementation similar to that encountered in industry

- $\quad$ To improve the written and oral communication skills of the students.

The proposed design of the bridge, as determined by a decision matrix designed by the students, was a parabolic arch that had its arched members angled into the centerline of the walkway as is shown in Figure 9. Although the basics of SAP2000 were previously understood by the students, 
this basic knowledge only served as issuing the students with the elementary tools required in performing the complex task of analyzing and designing the pedestrian bridge.

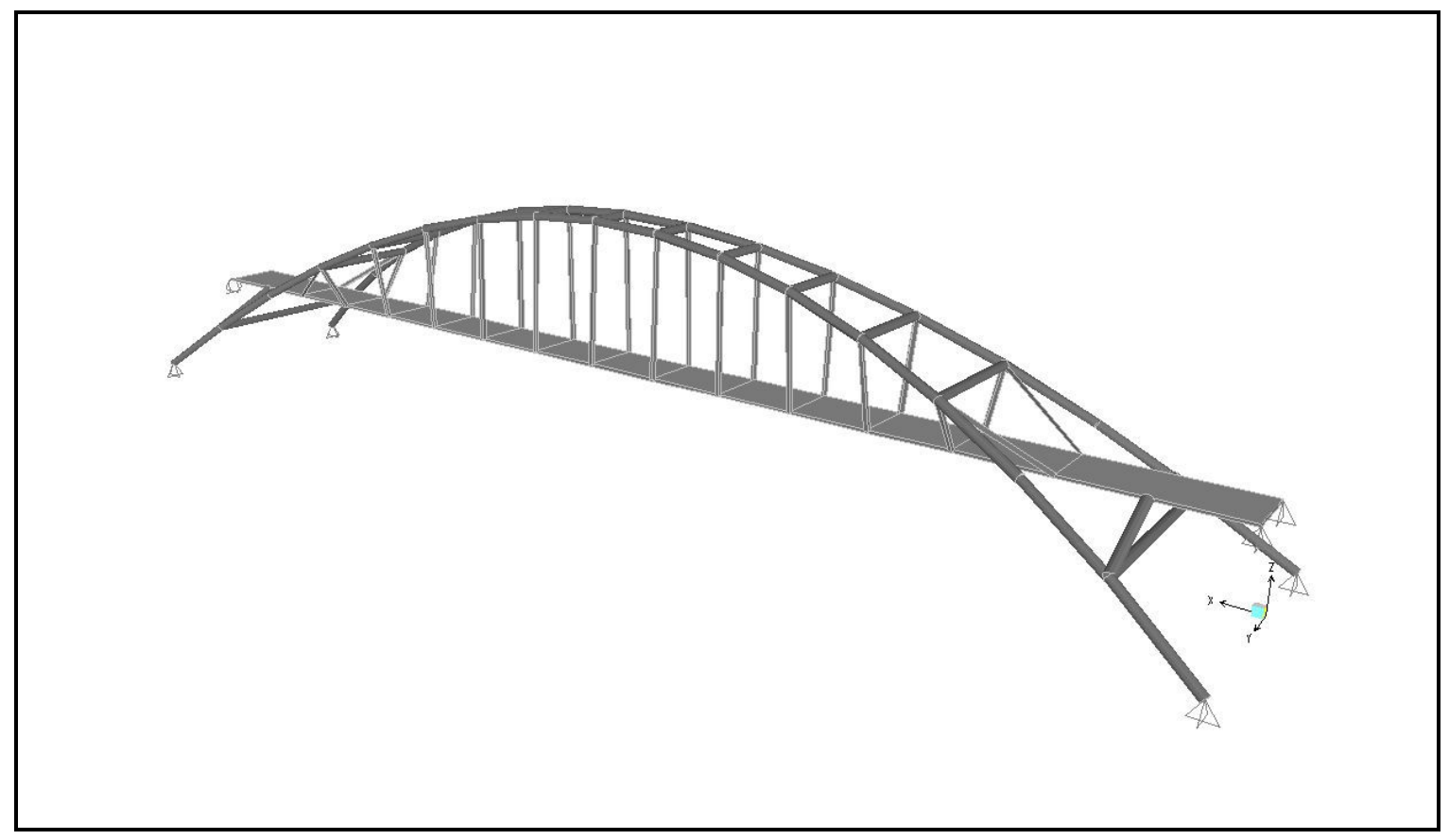

Figure 9. Extruded view of pedestrian bridge.

In the previous course projects, the students were given exact specifications and requirements to follow whereas for the senior design project, the group had to determine these requirements on their own. Using guidelines from the American Association of State Highway and Transportation Officials (AASHTO) Load Resistance and Factor Design (LRFD), the group embarked on the challenge of accurately modeling, analyzing, and designing the structure. Much of the knowledge that was required from the group to accomplish this task was found from them actually exploring the software on their own, building upon the foundation of the software that they had previously obtained through their structural engineering courses.

During the early stages of the modeling of the pedestrian bridge, the group found themselves coming across a problem of accurately designing the cable members which support the concrete deck. After a series of unsuccessful attempts at accurately modeling the cables, the group began to search SAP2000's documentation in hopes of determining a method to solve this problem. In the SAP2000's reference manual, the group found a tip stating that one could substitute a straight line object (i.e. an angle member) in place of a cable ${ }^{5}$. The documentation stated that this could be done when only the effects of the cables on the structure were needed to be known. Since cables can only support tensile stresses, all the group had to do was assign a frame compression limit of zero to all of the angled members to release them from carrying a compressive force. The releasing of forces in a member can only be accomplished during a nonlinear analysis in the software, so this option was selected for all of the load cases except for the instances where only gravity loads were being analyzed. 
Whereas the previous projects only used dead and live loads, the design of the pedestrian bridge required additional loading conditions to be analyzed. The two additional load cases that the group investigated were the wind loading condition as well as loading that would be applied to the structure from a moving service vehicle load. Applying the wind loading was made relatively easy through the "Apply Wind Loading" dialog box including in SAP2000. All that was required was for the group to assign a design wind speed in accordance to code requirements, enter the angle at which the wind would hit the bridge, and check that only the structural shapes would have the force of the wind applied to them. A sample of the deformed shape from the wind being applied perpendicular to the walkway of the bridge is shown in Figure $\mathbf{1 0 .}$

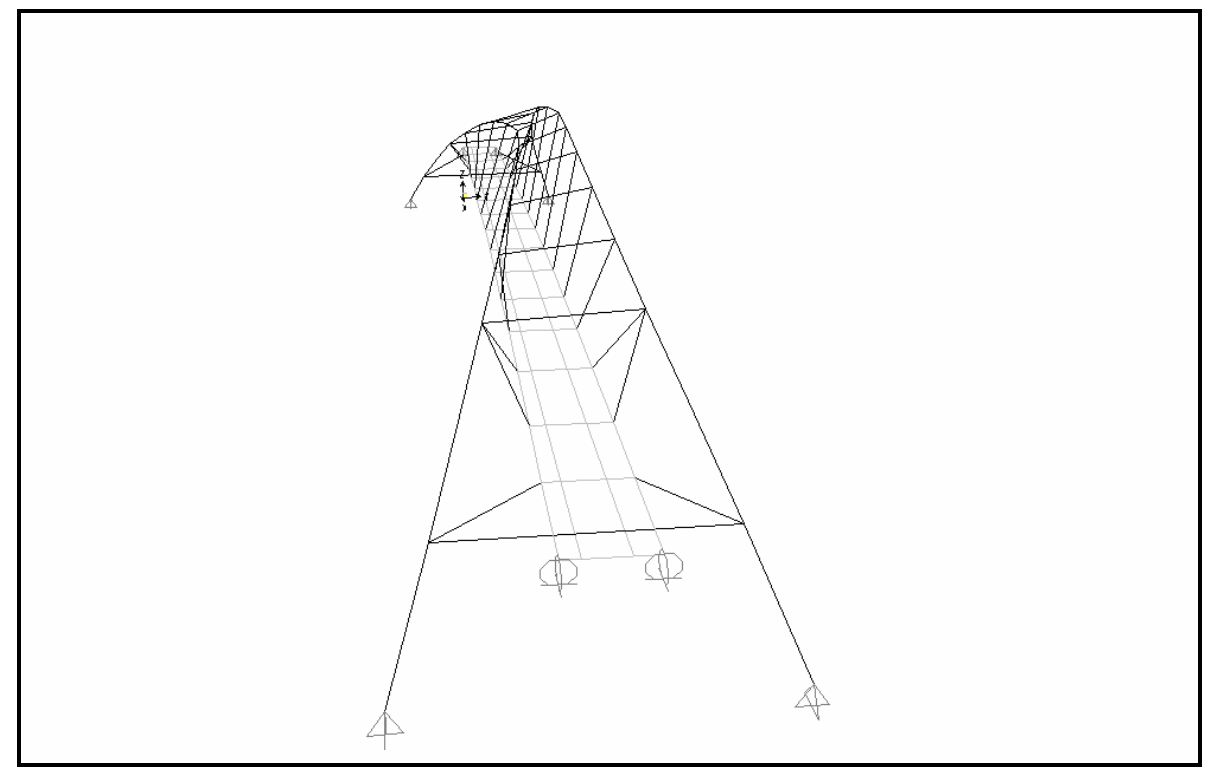

Figure 10. Deformed view of bridge with wind load applied.

The next major difference in analysis was that the bridge was analyzed with a moving service vehicle load. In order to apply the load as a moving load, the group had to first assign lanes to the walkway on the bridge. Once the lanes were defined, the next step was to assign the forces applied by the service vehicle load as well as the distance between each of these wheel loads. By assigning lanes for which the moving vehicle load can be applied allowed the group to view influence lines for the bridge. A sample of an influence line for the joint reaction at the base is shown in Figure 11. The group was able to display influence lines for reaction, axial, shear, moment, and torsional forces for all of the members on the structure.

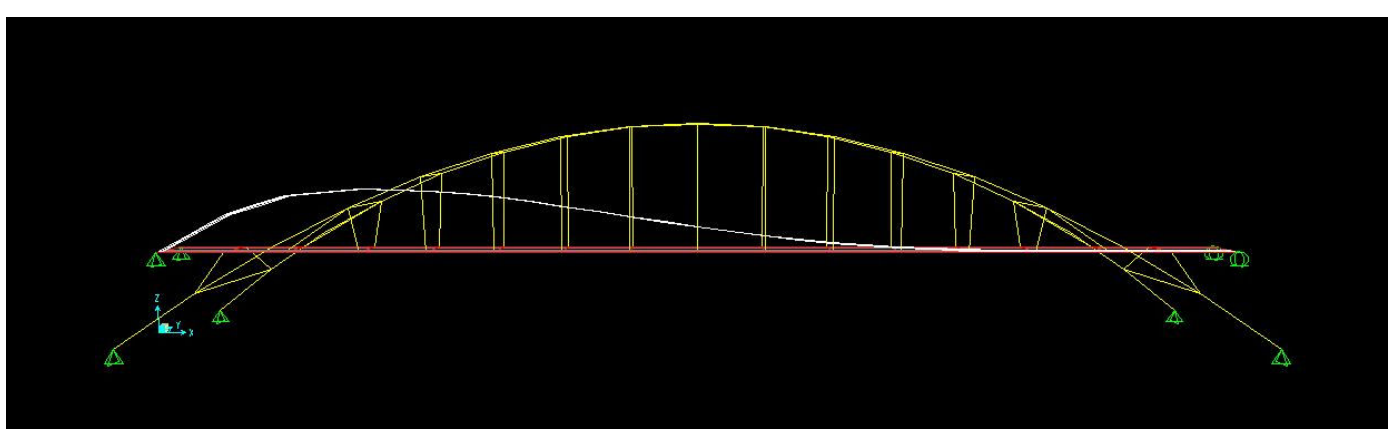

Figure 11. Influence line for joint reaction at base. 
The students themselves had to spend countless hours exploring the vast capabilities of SAP2000, and determine what features and functions would work for this real-world situation. Thus, the project fulfills the engineering department's goals for the senior design project, "...where students apply the knowledge and skills gained in the curriculum to a large-scale, team-oriented design project”.

\section{Student Survey}

After completing some or all of the aforementioned courses, the students were given a survey to gauge how they felt using computer analysis software helped prepare them for their futures as civil engineers. Whereas the survey conducted by Abudayyeh, et al. ${ }^{3}$ focused on practitioners and educators, the authors wanted to determine how students felt after using these two software packages throughout their time at the university. Questions asked to the students ranged from, "In which courses did you learn/use SAP2000/ETABS," to, "Do you think that SAP20000/ETABS strengthens your chance of getting a job?". For the first question, 56\% of the students had taken all three of the courses (Structural Analysis, Reinforced Concrete Design, and Steel Design), and thus had been exposed to the software packages throughout three different semesters. With Structural Analysis being a prerequisite course to the other two, all of the students had been at least exposed to SAP2000/ETABS at the time of the survey.

In addition to the three structural engineering courses, students also have SAP2000/ETABS available at their disposal for their Senior Design Project. Of the students whom are taking or have taken the Senior Design course, 100\% have used SAP2000/ETABS throughout various stages of their design projects. The students also responded in saying that using the software packages in their structural design of their projects has been very helpful (63\%), or helpful (37\%). Thus, $100 \%$ of those students that have used SAP2000/ETABS in their projects feel that using the software has at a minimum, been helpful in completing their projects.

Another question that was asked for the students was, "SAP2000/ETABS are very helpful for better understanding structural engineering concepts?" The majority of the respondents answered this question either strongly agree (33\%) or agree (44\%), with $23 \%$ answering disagree. With a broader range of answers on this question, it shows that these structural analysis software packages should not be used in place of teaching the fundamentals to students, but should instead be used as a supplement in further enhancing the learning process.

When asked if they recommended using SAP2000 and ETABS in structural engineering courses, $100 \%$ of the students either agreed or strongly agreed to the question. Although the vast majority of students only stated their familiarity with SAP2000 and ETABS was either good (33\%) or fair (44\%), $89 \%$ of the students felt that having background knowledge of these two software packages would strengthen their chance of getting a job. It should be noted that the only respondent to answer this question "Neutral" stated that, "I think it would help for students pursuing structural engineering, but I am not".

In addition to the previously discussed survey, all engineering students are required to complete two assessments of each course: one rating the course learning outcomes, and the other verifying 
that the ABET outcomes for the courses were achieved. For each of the courses in which SAP2000 and ETABS were incorporated into the curriculum, all students responded that the ABET outcome of, “.... an ability to use the techniques, skills, and modern engineering tools necessary for engineering practice” was achieved.

\section{Conclusion}

Accomplishing these projects successfully will not only refresh the student's background with the two software titles, but it can also refresh their comprehension of both structural analysis and design. It also supplies the students with very powerful tools needed not only to complete a senior design project successfully, but also to provide confidence while looking for their first job as the knowledge with a powerful design software packages is very attractive to many employers in the structural engineering field.

\section{Bibliography}

1. Grigg, Neil S., et al. "Integrated Civil Engineering Curriculum: Five-Year Review." Journal of Professional Issues in Engineering Education \& Practice 130.3 (2004): 160-165. Academic Search Premier. EBSCO. Web. 15 Nov. 2009.

2. Romero, Manuel L., and Pedro Museros "Structural Analysis Education through Model Experiments and Computer Simulation." Journal of Professional Issues in Engineering Education \& Practice 128.4 (2002): 170. Academic Search Premier. EBSCO. Web. 15 Nov. 2009.

3. Abudayyeh, Osama, et al. "Assessment of the Computing Component of Civil Engineering Education." Journal of Computing in Civil Engineering 18.3 (2004): 187-195. Academic Search Premier. EBSCO. Web. 15 Nov. 2009.

4. “About Computers \& Structures, Inc.”. http://www.csiberkeley.com/company_about.html. 7 Aug 2009.

5. Computers and Structures, Inc. CSI Analysis Reference Manual. Berkeley. CSI, 2008. 